\title{
PERSPECTIVES
}

OUTLOOK

\section{Follow-on biologics: data exclusivity and the balance between innovation and competition}

Henry Grabowski

Abstract | Legislation to create a regulatory pathway for follow-on biologics is currently being considered by the United States Congress. A critical issue in this respect is the period of data exclusivity for innovator companies before a follow-on competitor can rely in part on data obtained for an original biologic for an abbreviated approval. Given the nature of patents on biologics, the period of data exclusivity is anticipated to have a key role in determining how quickly follow-on competitors emerge, and consequently also on the time available for originator companies to recoup their investment. With this issue in mind, this article discusses factors influencing return on investment on biologic research and development. A break-even analysis for a representative portfolio of biologics provides support for a substantial data exclusivity period.

In the United States, most biologics are regulated through the Public Health Service Act. At present, this does not contain a mechanism for an abbreviated application for 'follow-on' versions of innovator biologics following patent expiry analogous to that which exists for generic chemical drugs under the Hatch-Waxman Act. Motivated by factors such as stimulating price competition with innovator drugs following patent expiry, the United States Congress is currently considering legislation that would create an abbreviated regulatory pathway for follow-on biologics, which are also referred to as biosimilars or biogenerics (for discussion of these acts, see REFS 1-3). As was the case when it created a regulatory pathway for generic chemical drugs through the Hatch-Waxman Act, Congress must balance innovation incentives and price competition. In addition, follow-on biologics raise complex scientific, regulatory and legal issues that differentiate these entities from generic chemical entries ${ }^{2}$.

One critical decision for legislators relates to the issue of the period of data exclusivity, which represents an important form of intellectual property for innovators. This is the period of time after US Food and Drug Administration (FDA) approval before a follow-on competitor can enter based on an abbreviated regulatory filing that relies in whole or part on the innovator's data on safety and efficacy. Without a data exclusivity period, there would be little incentive to invest in developing and marketing new product candidates with few remaining years of patent protection or with uncertain forms of protection. In addition, newly approved products with substantial commercial sales would be exposed immediately to legal risks associated with patent challenges and early entry of generic versions.

Data exclusivity and patents are complementary forms of intellectual property for new pharmaceuticals and biologics. The importance of patents to research and development (R\&D) innovation for new pharmaceutical therapies has been demonstrated in several economic studies ${ }^{4-6}$. Patents are a reward for innovation based on the criteria of novelty, utility and nonobviousness. Innovators generally apply for patents on compounds in the preclinical or early clinical phase of the development process. In the period after a patent is granted, but before a product can be marketed, innovators must generally perform a long, risky and costly investment process to demonstrate a product's safety and efficacy. Data exclusivity recognizes the substantial investment that innovators have to make in the data that demonstrate safety and efficacy to gain FDA regulatory approval. Ideally, data exclusivity would delay abbreviated filings and patent challenges until innovators have had an opportunity to earn a positive return on the new therapeutic candidates that successfully complete the lengthy and costly $R \& D$ process.

The Hatch-Waxman Act provides a 5-year data exclusivity period for new chemical entities (NCEs) before an abbreviated new drug application can be submitted (BOX 1, Note 1). By contrast, the European Union (EU) recently harmonized across member states a 10-year data exclusivity period for both NCEs and new biological entities (NBEs) before generic copies or follow-on biologics can be approved (BOX 1, Note 2). In addition, the EU provides for an additional year of data exclusivity for entities with significant new indications that are approved within the first 8 years after approval ${ }^{7,8}$.

Current US legislative proposals for follow-on biologics contain widely different provisions regarding data exclusivity. At one extreme, a bill introduced by Representative Henry Waxman (BOX 1, Note 3) would not provide for any data exclusivity for NBEs. On the other hand, the bill introduced by Representatives Jay Inslee, Gene Green and Tammy Baldwin provides for 14 years of data exclusivity (BOX 1, Note 3). A bipartisan Senate bill, co-sponsored by Senators Kennedy, Enzi, Clinton and Hatch, has a 12 -year exclusivity provision. Recently, a House bill introduced by Representatives Eshoo and Barton has a 12-year exclusivity provision plus 2 years for a new indication and 6 months for paediatric exclusivity (BOX 1, Note 3).

Data exclusivity assumes particular importance for biological entities as compared with chemical entities because many of these products rely on narrow patents that 


\section{Box $1 \mid$ Additional notes}

Note 1 . The new chemical entity (NCE) data exclusivity period under the Hatch-Waxman Act affords new molecules a floor of effective exclusivity from generic entry through the abbreviated new drug application (ANDA) process for 5-7.5 years, depending on how long courts take to resolve patent suits. The Act has a stay on generic entry of up to 30 months beyond the 5 -year exclusivity period while court cases are in progress ${ }^{1}$.

Note 2. Generics firms can submit abbreviated applications to the regulatory authorities 8 years after approval of the original molecule, but the earliest these applications can become effective is when the 10-year exclusivity period expires.

Note 3. Representative Waxman introduced H.R. 1038, The Access to Life-Saving Medicine Act, in the House and Senators Clinton and Schumer introduced an identical companion bill in the Senate, S. 623. Representatives Inslee, Green and Baldwin introduced H.R. 1956, Patient Protection and Innovative Biologic Medicines Act. Senators Kennedy, Enzi, Clinton and Hatch introduced S. 1695, Biologics Price Competition and Innovation Act of 2007. Representatives Eshoo and Barton introduced H.R. 5629, The Pathway for Biosimilars Act, in the House in March 2008. For an analysis of the different features of the alternative Congressional bills on follow-on biologics, see REF. 46.

Note 4. A patent's validity can be challenged on grounds such as obviousness, anticipation by the prior art or double patenting. A court may determine, for example, that a drug invention was "obvious", allowing the generics challenger to enter if the data exclusivity period has expired. The issue of patent type is also relevant from a policy standpoint. Process, method of use, and formulation patents have less breadth than product patents and may be more vulnerable to challenge on the grounds of validity or non-infringement, although each situation must be evaluated on a case by case basis. As of June 2002, the US Federal Trade Commission (FTC) reported that generics firms had won the vast majority of suits, but most of the cases with outcomes at that time involved late-stage process or method patent challenges ${ }^{47}$.

Note 5. Most of these patent challenges now occur 4 years after market approval, which is the earliest point in time that a generics firm can submit an ANDA filing with a certification for challenging patents validity or asserting non-infringement ${ }^{12}$. The first generic to successfully file and win its patent suit gets an 180-day exclusivity under the Hatch-Waxman Act.

Note 6. For a general description of the discovery and development pathway for new drugs and biologics, see REF. 48.

Note 7. Janet Woodcock of the US FDA noted that: "Even well-characterized, highly purified recombinant proteins may exhibit minor degrees of structural variability from lot to lot resulting from variants in the manufacturing process. The quality and nature of natural source products can vary depending on the condition of the source material, processes used to extract and purify the product and other factors." ${ }^{45}$ Validation of a biological manufacturing process involves many complex activities and even minor changes in this process can affect a product's quality and properties that necessitate additional testing.

Note 8 . The starting point is the initiation of Phase I trials by the company performing the clinical investigations, rather than the filing of the investigational new drug application, which is often much earlier in the timeline.

Note 9. For a detailed discussion of the methodology and data issues associated with estimating R\&D costs in pharmaceuticals, see REFS 21,49 . Since these papers were published, a follow-on paper on this topic was published by FTC economists using alternative data sets, which found comparable estimates for RED costs to our earlier paper, including significant variability across therapeutic classes ${ }^{50}$. It is worth pointing out that the therapeutic area with the greatest concentration of biological entities — oncology — has significantly higher RED costs than the mean compound (US\$1.016 billion compared with $\$ 868$ million for the mean compound $)^{50}$. This paper focuses on an earlier period than REF. 16 , but is generally consistent with the estimates in that analysis after allowing for time-related adjustments in the growth of R\&D costs.

Note 10. A real cost of capital adjusts for the effects of inflation. Assuming a historical rate of inflation of 3-3.5\%, the corresponding nominal cost of capital would be approximately $15 \%$. Our cost of capital estimate is based on a capital asset pricing model analysis for a small set of biotechnology firms with a history of profitability based on multiple marketed products. These companies also had an extensive portfolio of new biological product candidates over the period 1990-2003 (REF. 16). make them more vulnerable to challenges from follow-on competitors. Although biologics typically have multiple patents on various elements of the active agent ${ }^{9}$, several scientific and legal developments have operated over time to constrain the scope of recent biological patents ${ }^{10,11}$. Data exclusivity provides an important back-up to the patent system in those cases in which follow-on competitors could circumvent narrowly drawn patent claims and gain early entry through abbreviated applications. As follow-on biologics will be comparable but not identical to the innovator's molecule - and may also use different methods of formulation and manufacture - they may avoid infringing the innovator's core patents, while still being able to gain regulatory approval through an abbreviated pathway. Each situation must be examined on a case by case basis in this respect.

Generics firms have strong incentives to challenge patents early in a product's life cycle in order to gain first-mover or early-mover competitive advantages $^{12}$ (BOX 1, Note 4). Multiple lawsuits involving infringement have become the rule under the HatchWaxman Act for commercially important drugs early in the brand product's life cycle (BOX 1, Note 5). As a percentage of abbreviated new drug application filings, they have increased from $2 \%$ during the period $1984-1989$, to $12 \%$ from 1990 to 1997 , and to $20 \%$ from 1998 to 2000 (REF. 13). While all patent litigations are costly and introduce additional risks to innovators, patent challenges in the early stages of marketing have especially adverse consequences because they occur many years before break-even returns for new medicines. This prospect can be especially troublesome for early stage biopharmaceutical firms, because funding is typically supplied by venture capital firms that are very sensitive to uncertainties and risks about intellectual property protection.

With these issues in mind, this paper presents some of the key factors that influence the optimal length of the data exclusivity period from an economic perspective, and provides a break-even analysis for a representative biologic portfolio. This analysis is used as a basis to discuss the implications for ongoing policy discussions about follow-on biologics.

\section{Optimal exclusivity times}

Beginning with the pioneering work of William Nordhaus ${ }^{14}$, economists have developed conceptual models to determine the socially optimal exclusivity time. Exclusivity can originate from patents and 


\section{Box 2 | RED timelines for bevacizumab (Avastin)}

The long timelines for the introduction of new biological entities are illustrated by the discovery and development process for bevacizumab (Avastin; Genentech/Roche), the first of a new class of drugs to treat colorectal cancer ${ }^{36,55}$. In 1989, Napoleone Ferrara, a scientist working for Genentech, isolated vascular endothelial growth factor (VEGF). Then, in 1993, Ferrara and his team published a key study demonstrating that an anti-VEGF antibody can suppress angiogenesis and tumour growth in preclinical models. However, it was not until 1996 that Genentech scientists were able to humanize an anti-VEGF antibody, and Genentech submitted an investigational new drug application for this antibody, now known as bevacizumab, to the US Food and Drug Administration in 1997. The first Phase I trial for bevacizumab began that same year and was followed by a Phase II trial in 1998. In 2000, a Phase III trial began to evaluate the use of bevacizumab to treat first-line metastatic colorectal cancer, which took 3 years. Finally, in February 2004, 15 years after the isolation of VEGF by Ferrara, the FDA approved bevacizumab as the first anti-angiogenic drug for treating cancer.

from complementary forms of intellectual property protection such as data exclusivity. The basic trade-off is between incentives for new product development versus more intensive price competition after exclusivity expires. In particular, longer exclusivity times encourage increased development of NBEs and NCEs as well as additional research on new indications for established products. However, longer periods can also postpone the onset of competition from generics. When the additional benefits from expected development of more new medicines are just equal to the additional costs of postponing the onset of competition from generics, the exclusivity time is considered optimal from an economic perspective.

While this theoretical modelling has not yielded a specific value for the optimal exclusivity time for biopharmaceuticals (or any other industry), it does provide a framework to assess which industry characteristics are relevant to current policymakers' decisions in this regard. In particular, for industries in which the R\&D process is costly and risky, longer exclusivity periods to realize innovation benefits are needed in comparison with those industries in which innovation is easier and less costly. Similarly, when the output of innovation has important external benefits to society - as in the case of new medicines and new indications for existing medicines - this also supports a longer exclusivity period ${ }^{15}$. The next two sections review what is known about the basic characteristics of innovative activities for new biologics.

\section{Characteristics of RED activity for NBEs} Sources of risk for candidate NBEs. The R\&D process for NBEs is fraught with many risks. It is common for the development of an NBE to originate in a start-up company financed through venture capital financing. At the initial stages of development, there is a high degree of scientific risk associated with proof of concept. Preclinical data are used to gain insights into expected efficacy, toxicity and pharmacological effects once a lead agent is identified. Even when animal studies indicate promise, they imperfectly predict human response concerning safety and efficacy. This is one important reason for high attrition in clinical trials (BOX 1, Note 6).

As a candidate NBE moves through the clinical-trial process, there are additional risks of failure due to difficulties involving formulation, manufacturing scale-up or inconvenient dosing regimens. As biologics are complex molecules produced from cultures of living cells, manufacturing and engineering process issues at the $\mathrm{R} \& \mathrm{D}$ stage can pose greater challenges than for chemically synthesized compounds. Process specifications and manufacturing know-how are critical elements for NBEs (BOX 1, Note 7).

Several economic studies confirm that the R\&D process for NBEs is subject to large risks from scientific, regulatory and economic factors. An analysis of the probability of success of 522 biological candidates at various stages in the clinical development process found that the overall probability of success in clinical development was $30 \%$ (that is, the success rate of candidates that make it as far as trials in humans $)^{16}$. While biologics had higher overall success rates than chemical drugs, they have had lower success rates in the most expensive Phase III trials, indicating that biologics that fail in clinical trials often do so only after high development costs have been incurred. A recent study by Goldman-Sachs ${ }^{17}$ also found that Phase III success rates of biologics from 1995 to 2003 are lower than those of pharmaceuticals, and have exhibited a significant downward trend over time. This downward trend is consistent with the fact that the complexity of biological products under development has increased, a phenomenon that is also reflected in longer development times.

Development times. The development process for an NBE is lengthy and typically spans more than a decade. The discovery and preclinical process is subject to considerable uncertainty and variability, especially when a new class of drug or new target receptor site is being investigated. This is illustrated by the example of bevacizumab (Avastin; Genentech/Roche; BOX 2).

FIGURE 1 shows the mean clinical development time to FDA approval for NCEs and NBEs from REF. 16, which found that the average development time for an $\mathrm{NBE}$ was 97.7 months, compared with 90.3 months for small-molecule or chemical drugs (BOX 1, Note 8). And, as shown in FIG. 2, development times for NBEs have increased steadily since the early 1980s. At the beginning of the 1980s, the majority of NBEs receiving marketing approval were proteins with wellunderstood functions. As this initial group was exhausted, the industry has turned to more complicated, less well-understood targets, and development times have steadily increased. This is true despite the fact that average FDA review times have decreased significantly since the 1980s for NCEs and NBEs as a result of the Prescription Drug User Fee Act ${ }^{18}$.

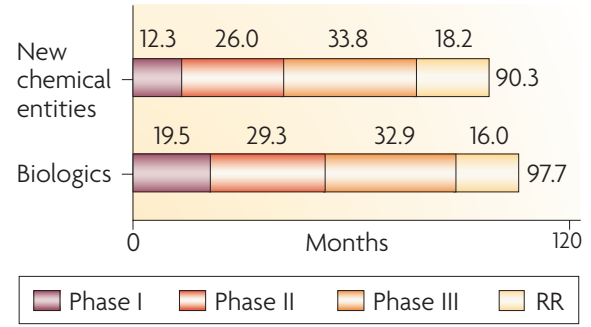

Figure 1 | Clinical development and approval times for chemical drugs and biologics. The average development time for a new biological entity was 97.7 months compared with 90.3 months for small-molecule or chemical drugs. A significant part of the difference is associated with a lengthier Phase I process for biological entities. After a new pharmaceutical or biologic is approved, there is frequently substantial additional research and development activity involving investigations for new indications or formulations. In addition, the US Food and Drug Administration may require post-approval Phase IV studies as a condition of approval. Development times include only clinical phases and regulatory review (RR) periods; preclinical times are not included. 


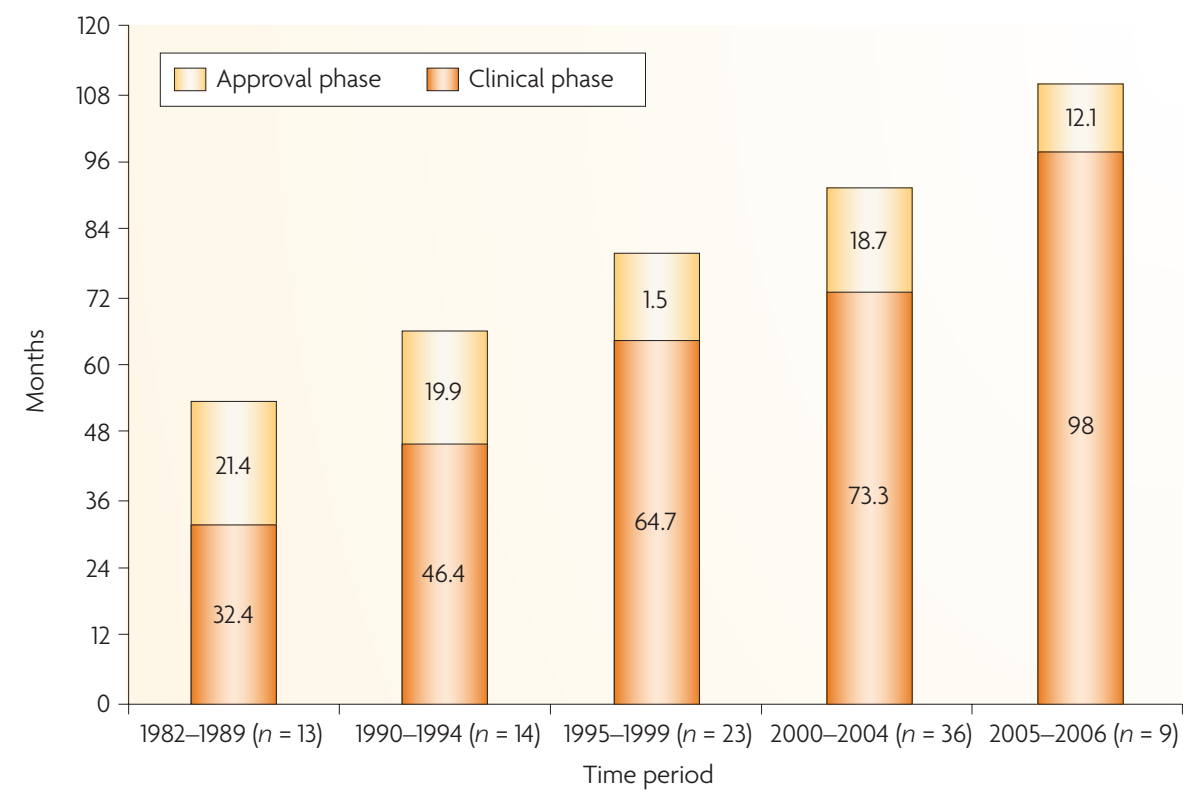

Figure 2 | Development times for new protein therapeutics. Development times for new biological entities (defined here as new protein therapeutics, including new recombinant proteins, monoclonal antibodies and non-recombinant proteins) have increased steadily since the early 1980s. This figure is based on data collected by the Tufts University's Center for the Study of Drug Development from several time cohorts of US Food and Drug Administration approvals.

Development costs. $\mathrm{R} \& \mathrm{D}$ costs for new biologic introductions have also been analysed $^{16}$ (BOX 1, Note 9). Data were collected to estimate the expected costs at each phase of the cycle, and were then risk-adjusted for the expected probability of success at each stage of the development life cycle. Using this approach, it was found that total out-ofpocket costs for the preclinical and clinical periods exceed US\$500 million. Time costs were also taken into account by capitalizing out-of-pocket costs to the date of marketing approval. This study found that the capitalized $R \& D$ costs for a representative NBE range from $\$ 1.24$ billion to $\$ 1.33$ billion when the real cost of capital is 11.5-12.5\% (BOX 1, Note 10). As discussed below, the average cost of capital for NBEs in early stage companies will be much larger than this $11.5-12.5 \%$ range that is estimated for a small set of established biopharmaceutical firms ${ }^{19,20}$ (BOX 3, Note 1).

It was found that $\mathrm{R} \& \mathrm{D}$ costs for NBEs are comparable in magnitude to earlier estimates involving chemical drugs ${ }^{21}$ when the latter estimates are time-adjusted to take into account differences in the time periods analysed. However, the underlying cost components differed significantly. As noted, biologics have higher probabilities of clinical success overall, but lower probability of success in the more expensive
Phase III trials. Biologics also have higher discovery and preclinical expenditures and longer mean clinical development times. It was also found that the development of biologics involve higher development costs associated with process engineering and manufacturing than is true for chemical drugs. This reflects the need to resolve novel manufacturing challenges at the R\&D stage. By contrast, manufacturing process issues in $\mathrm{R} \& \mathrm{D}$ are typically more straightforward for drugs based on chemical synthesis (BOX 3, Note 2).

\section{Market structure and skewed sales distribu-} tion. The sales of NBEs that do make it to the market exhibit tremendous variability, which represents another source of risk. As is the case for chemical drugs, the sales distribution for NBEs is highly skewed, with relatively few compounds accounting for a disproportionate share of sales and profits. An analysis of 30 NBEs introduced from 1982 to 1994 indicated that the top one-fifth ranked entities accounted for roughly $70 \%$ of the total 2002 sales $^{22,23}$. Biologics that rank in the top few deciles of the sales distribution are frequently 'best in class' or 'first in class' therapies. In addition to direct competition from new molecules in the same class, they also would be the primary targets of generic biologic firms.
Intellectual property and the financing of biotechnology ReD projects. Intellectual property is a key dimension of the decision to invest in life-science companies that have little other tangible or intangible assets and a lengthy period of clinical trials before marketing approval. If an abbreviated application process is created by the United States Congress for follow-on biologics, data exclusivity will become an important aspect of the calculation of risks and rewards by private and public markets.

Given the characteristics of the R\&D process, some important implications follow for the financing of R\&D investment in an innovative entrepreneurial industry like biopharmaceuticals. First, in the early stages of development, it is crucial to have the support of financial institutions such as venture capital firms that can take a relatively long view and a portfolio approach to such risky investments ${ }^{24}$. Second, if the relatively few large successes experience increased uncertainty due to patent challenges and the potential for early entry of generic versions, higher risk-adjusted rates of return will be demanded by venture capital firms as well as in initial public offerings and secondary offerings in public markets, yielding fewer candidates that meet this standard. Early stage R\&D in start-up firms will be the most likely affected segment. Such a prospect is a particularly unfavourable outcome for firms and industries whose products contribute to important long-term advancements in public health.

For NBEs that are developed internally by large, established biotechnology or pharmaceutical firms, similar considerations must also be confronted in portfolio decisions. Product candidates with significant uncertainty from expected legal challenges soon after marketing launch would have diminished economic prospects relative to other investment-stage candidates.

\section{Importance of biologic innovation}

When innovation has important benefits for overall social welfare, this provides support for a longer exclusivity period. There is accumulating empirical evidence that new medicines and therapies have played an important role in increased longevity, enhanced quality of life and improved labour-force productivity ${ }^{25-27}$. Furthermore, recent studies have found that consumers have appropriated significantly more of the societal benefits than innovators in the case of new therapies for HIV/AIDS, as well as several other new technologies ${ }^{28,29}$. 
The biotechnology industry is a relatively new source of medical innovation; it had its first new drug product approvals in the early 1980s. However, it has become a major source of novel drug introductions and overall industry growth in recent years. A recent paper examining the quantity and quality of worldwide new drug introductions between 1982 and 2003 found that biotechnology drugs are the fastest growing segment of new therapeutics: they accounted for $4 \%$ of new drug introductions in the 1982 to 1992 period, which grew to $16 \%$ in the 1993 to 2003 period $^{30}$. In addition, US firms are the dominant source of drugs from biotechnology companies, originating more than half of all worldwide biopharmaceutical introductions from 1982 to 2003.

Although not the only measure considered in this analysis, one of the key indicators of drug quality or novelty was first-in-class introductions, and NBEs had a significantly higher likelihood of being a first-in-class or novel therapy compared with NCEs. NBEs have been particularly focused on oncology and immunological areas in recent years. Given the increased knowledge of the molecular bases for cancer, the oncology class has been characterized in recent years by the introduction of breakthrough monoclonal antibodies and other targeted biological agents. These include rituximab (Rituxan; Genentech/Biogen Idec), trastuzumab (Herceptin; Genentech/Roche) and bevacizumab (Avastin; Genentech/Roche).

Several NBEs have had rapid uptake and are among the leading drug therapies in their class from a therapeutic perspective. Furthermore, these products are being investigated for a number of new indications at present. Substantial improvements in survival, morbidity and patients' quality of life have been documented in diseases previously resistant to successful treatment, including cancers such as aggressive HER2 (also known as ERBB2)-positive breast cancer $^{31}$ and gastrointestinal stromal tumour $^{32}$, as well as in preventing the disease progression, functional decline, joint destruction and disability associated with rheumatoid arthritis ${ }^{33}$.

The prospects of future advances are further enhanced by a strong pipeline of more than 400 biotechnology drugs under development in various therapeutic areas ${ }^{34}$. These include novel approaches to conditions with large disease burdens, including 200 biotechnology drugs for cancer alone. Early stage R\&D of a novel drug is fraught, of course, with high risks, but can also yield both high potential rewards to investors as

\section{Box 3 | Additional notes}

Note 1. Grossman ${ }^{19}$ estimates that biotechnology firms without a marketed product but with one or more drug candidates in Phase II or III trials have an average nominal cost of capital of $27.4 \%$. He also estimates a nominal cost of capital for biotechnology firms with at least one drug approved of $18.7 \%$. Myers and Shyum-Sunder ${ }^{20}$ estimated a $14 \%$ real cost of capital for a group of publicly traded biotechnology firms for an earlier period. As noted, our $11.5 \%$ real cost of capital is based on a smaller group of biotechnology firms that have multiple products and a history of positive operating profits over the past decade.

Note 2. It is important to note that the costs of constructing a new manufacturing facility or retrofitting an existing plant for large-scale commercial production are not included in the RED cost estimate. The cost of a new multi-product manufacturing plant is substantial in the case of biologics. In particular, it has been estimated that a new manufacturing plant can take 3-5 years to build, and cost US $\$ 250$ million or more ${ }^{51}$. Even retrofitting an existing plant can cost between $\$ 50-100$ million.

Note 3 . While generics typically capture the dominant share of the market within a short time after entry for commercially successful pharmaceuticals, innovative firms can retain some of the market in the post-patent expiration period through authorized generics (albeit at significantly reduced prices and margins $)^{13}$. Another strategy that is sometimes successfully used by innovators is to develop an improved formulation (for example, an extended-release product) before the patent expiration of the basic molecule. These new formulations must be submitted to the US FDA for approval with new clinical-trial data demonstrating efficacy and safety. They are then eligible for a 3-year exclusivity period. Companies may also be able to obtain additional patent protection for new formulations, but formulation patents are more susceptible to challenges on the grounds of obviousness and other points, and also easier to invent around by generics firms. The recent Supreme Court ruling in KSR versus Teleflex raises the bar on the non-obviousness criterion for patents, and makes improvement patents more vulnerable to challenges on the grounds of obviousness ${ }^{52}$.

Note 4. These trends were examined in REF. 12 along with the case for longer data exclusivity periods under the Hatch-Waxman Act. This could be patterned along the lines of current European Union (EU) policies. Since this paper was published, these adverse trends have intensified. Doug Long, Vice President of IMS, in a recent presentation provided data that demonstrated the growth in total prescriptions for generic products since 2001 has significantly exceeded that for branded pharmaceutical products ${ }^{53}$. Generics currently account for $67 \%$ of all prescriptions dispensed in the United States. The fastest growing segments of the pharmaceutical industry are now generics and biologics.

Note 5. It is important to include post-approval R\&D costs in the break-even analysis, given that sales values in the analysis include revenues from new indications and formulations as well as the original indication. To take account of post-launch RED expenditures, I assume they will be $35 \%$ of the out-of-pocket expenditures for pre-approval RED costs. This yields total cash outlays of $\$ 195.6$ million spread evenly over the first 8 years after launch ( $\$ 24.5$ million per year). These assumptions are consistent with our analysis of new drug introductions ${ }^{40}$. It is reasonable to assume that expenditures on new indications and formulations for biotechnology drugs are proportionately as large as for new drug introductions, given RED pipeline data and the analysis of Calfee ${ }^{27}$.

Note 6. Based on prior work, here it is assumed that there will be $\$ 25$ million in plant validation costs per product introduction (\$12.5 million per year), as these costs are not captured in our R\&D cost estimates.

Note 7. Alternatively, this approach is akin to assuming production is outsourced with a contract manufacturing charge equal to book depreciation charges. This also would be a conservative assumption as contractors would have to obtain a margin above depreciation costs to be a viable business.

Note 8. Contribution margins are defined as sales minus the costs of goods sold (including depreciation charges for plant and equipment), marketing, promotion and administrative costs in the numerator. This is expressed as a percentage of sales in the denominator.

Note 9 . It is assumed here that total expenses exceed sales by $30 \%$ in year 1 , and the contribution margin in year 2 is equal to $20 \%$. In addition, in the 2 years before market introduction, it is assumed that there are launch-related expenditures equal to $10 \%$ and $20 \%$ of the first year's sales. These values are based on information collected in conjunction with new drug introductions ${ }^{40}$.

Note 10. Even if therapeutic equivalence is not granted by the FDA, managed care organizations can be expected to use various incentives to facilitate the use of follow-on biologics as therapeutic alternatives. Formulary decisions and other actions will be used by managed care organizations to encourage the usage of follow-on biologics after their pharmacy and therapeutics committees ascertain their comparability to the relevant branded product. In this regard, an Avalere Health study ${ }^{54}$ projects a market share for biosimilars of $60 \%$ of the total units of the molecule 3 years after their launch onto the market, assuming they compete as therapeutic alternatives rather than substitutes. This compares to market penetration of generics in the range of $90 \%$ for the largest selling chemical molecules over shorter time intervals ${ }^{12}$. 


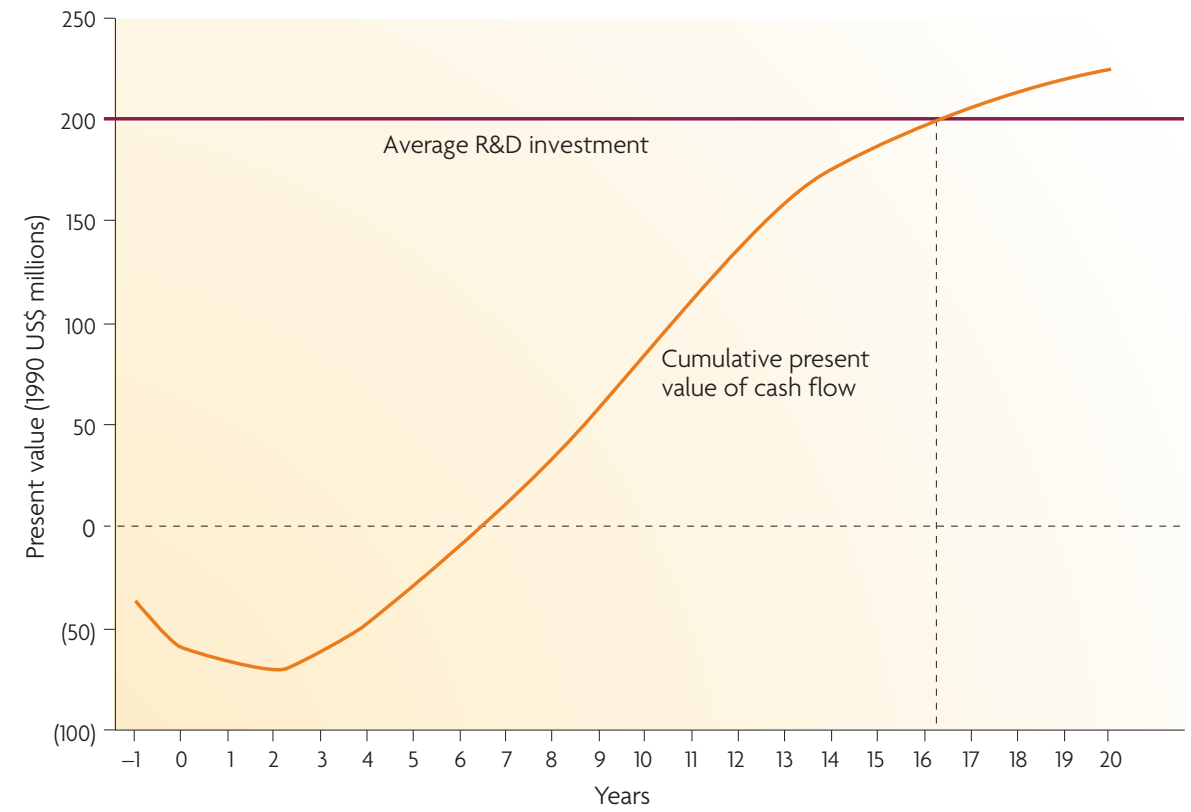

Figure 3 | Cumulative present value of cash flow versus R\&D investment for the mean new chemical drug introduced between 1980 and 1984. The analysis combines data from analysis of research and development (RED) costs and cash flows from this cohort of 1980-1984 introductions. The break-even lifetime for the mean drug in this portfolio is just over 16 years. In particular, this is where the present value of cumulative after-tax cash flows just intersects the present value of after-tax RED investment (all measured in 1990s US dollars), signifying the fact that the firm has recouped its investment plus a return equal to the industry's average cost of capital for that period. Data from REF. 38.

well as large therapeutic benefits to patients. It is important that such high-risk endeavours have sufficient economic prospects for returns to undertake the long, costly and risky investment process.

In a recent paper, Calfee and DuPre pointed out two important features of competition involving $\mathrm{NBEs}^{35}$. First, after proof of principle has been established for a new biologic, multiple therapeutic interventions are possible in the biological cascade of proteins that often influence the same ultimate target (for example, a particular receptor or dysfunctional enzyme). For example, in the case of trastuzumab there are more than ten targeted drugs currently in Phase II or III for breast cancer targeting the HER2 receptor, other members of the HER family, or one of the other proteins downstream from HER2. The tumour-necrosis factor (TNF) inhibitors for rheumatoid arthritis and anti-vascular endothelial growth factor (VEGF) drugs for cancer are also experiencing similar forms of competition involving the same targeted pathways, but with different modes of action.

A second important feature of competition for NBEs involves new indications associated with the same or related pathways. For example, drugs that were initially approved for rheumatoid arthritis are being investigated for a number of anti-inflammatory conditions that may be related to the same dysfunctional pathway. For example, two of the leading anti-TNF drugs for rheumatoid arthritis, etanercept (Enbrel; Amgen/Wyeth) and infliximab (Remicade; Centocor), have received subsequent approval for psoriasis and Crohn's disease, respectively, and more than $20 \mathrm{clini}$ cal trials are in progress for bevacizumab in different types of cancer and different stages of cancer $^{36}$.

The development of new indications for established biologics would be particularly vulnerable to early patent challenges by generics firms seeking to enter based on an abbreviated pathway. This is because obtaining approval for a new indication postapproval can take several years and involve large-scale patient trials and significant costs. The uncertainty surrounding early patent challenges may tilt the risk-return balance against otherwise economically viable investment programmes for new indications. In this case, patients would be deprived of health benefits from new indications that in many cases are equivalent to or surpass those of the original approved indications ${ }^{35,37}$. Although it might be possible for a firm in this situation to get a new use patent for the new indication, these patents are difficult to impossible to enforce against a generic entrant that manages to get an approved label for a more limited set of indications.

Prior analyses of break-even lifetimes Data exclusivity provides an investment return period before imitators can enter with an abbreviated application that relies on the innovator's data. It is therefore instructive for the current analysis to examine the minimum time required by a representative portfolio of new therapeutic agents to achieve break-even status from an economic perspective - that is, to cover its R\&D costs and earn a risk-adjusted return on capital. To do so, one needs information on R\&D costs and other cash outlays and inflows over the full product life cycle. To date, this issue has been investigated in a comprehensive way for new molecular entities introduced in the 1980s and 1990s. The sample of drugs investigated has consisted primarily of NCEs. A few of the initial biological entities that were introduced in the 1980s and early 1990s were also included in the analysis.

The break-even lifetime is illustrated in FIG. 3 for the 1980-1984 portfolio of $\mathrm{NCEs}^{38,39}$. The break-even lifetime for the mean drug in this portfolio is just over 16 years. A similar analysis for the 1990-1994 portfolio of NCEs gives a break-even lifetime of 15 years $^{40}$. By contrast, the average market exclusivity periods observed for new molecular entities experiencing initial competition from generic versions in the 1996-2005 period generally fluctuated between 12.5 and 15 years on an annual basis with substantial variation across individual entities (BOX 3 , Note 3 ). There was also a declining trend observed for the molecules with the largest commercial sales that are the principal targets of patent challenges ${ }^{41}$. As noted previously, the distribution of NCEs is highly skewed. A few blockbuster new drug introductions earn several times the mean $R \& D$ costs and can achieve a break-even point much faster. But it must be kept in mind that only $30 \%$ of the sample of NCEs have cash inflows that exceed the average R\&D outflows in present value terms. Hence, the blockbuster products with large commercial sales compensate for the large number of products that never break-even from a net present value standpoint.

With the high degree of risk and uncertainty that exists for R\&D in new therapeutics, including biologics, it is difficult to predict in advance which or whether any products in a particular portfolio will be big winners. Many products start with this objective but end up as incremental 


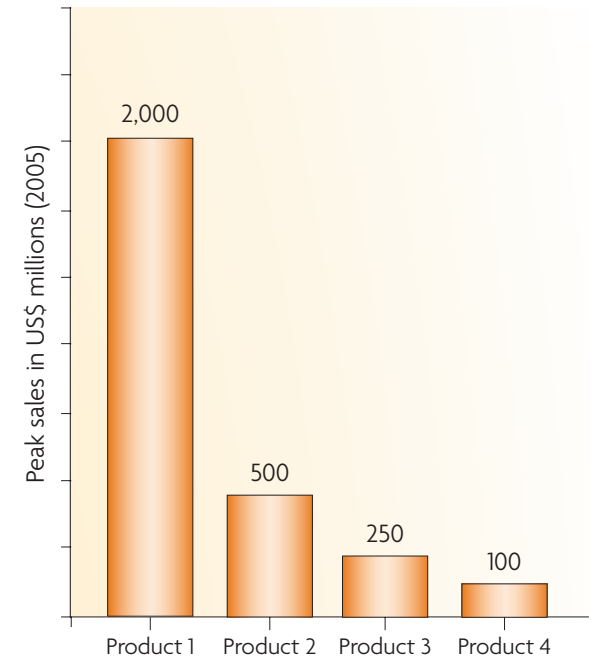

Figure 4 | Model portfolio based on sales distribution for established biological products. The peak revenue values are shown for a fourproduct 'stylized' portfolio. This portfolio reflects the mean values observed for the top four ranked quintiles of the sales distribution of established biotechnology drugs.

advances or fall by the wayside. This is why venture capital firms and biopharmaceutical firms take a portfolio approach. In effect, the few highly successful new pharmaceutical entities have a key role in covering the large fixed costs of $R \& D$ and enable the entire portfolio to achieve a positive risk-adjusted rate of return.

Whether this blockbuster model for success in pharmaceuticals can be sustained is uncertain given the trends towards higher $\mathrm{R} \& \mathrm{D}$ costs for new drug introductions, together with shorter product lifetimes for commercially successful drugs and intensifying competition from generics (BOX 3, Note 4). One of the primary strategies used by pharmaceutical firms to deal with these adverse trends is increased acquisitions and partnerships with biotechnology firms ${ }^{42,43}$.

\section{Break-even lifetimes for NBEs}

Only a few biological entities have been included in prior analyses of R\&D returns, given the long time frames that these studies require and the relative youth of the biotechnology industry. However, for current purposes, it is instructive to undertake an analysis that simulates the break-even lifetimes for NBEs launched in the present time frame with different projected sales revenues.

In the break-even lifetime analysis presented here, the annual R\&D costs for an NBE from the analysis in REF. 16 for the preapproval period are used. This is combined with a plausible estimate of post-approval
$\mathrm{R} \& \mathrm{D}$ costs for new indications and formulations (BOX 3, Note 5). Using this R\&D investment information, the break-even lifetimes for a portfolio of new biotechnology products with peak sales of different values are considered. In particular, this model portfolio is constructed using values on peak sales that approximate the distribution on sales revenues for 30 mature biotechnology products analysed in REFS 22,23.

Sales profiles. In FIG. 4, the peak revenue values are shown for a four-product stylized portfolio. This portfolio reflects the mean values observed for the top four ranked quintiles of the sales distribution of established biotechnology drugs. In particular, biotechnology drugs in the highest ranked $20 \%$ cohort had mean sales of approximately $\$ 2$ billion. The next three quintiles had means of $\$ 500$ million, $\$ 250$ million and $\$ 100$ million, respectively. The bottom quintile, accounting for the lowest ranked $20 \%$ of the products in the sales distribution, is excluded because many of these small-selling biologics were approved under the Orphan Drug Act and may not have representative R\&D cost profiles. However, excluding all the biologics in the lowest tail of the distribution makes the current analysis conservative and biases break-even lifetimes downward.

We can focus on a stylized portfolio of four products without loss of generality as peak sales are based on historical values for the top four quintiles of the sales distribution. A representative sales life cycle for these four marketed products can be constructed using the annual sales profile realized by the average new drug introduction in the $1990 \mathrm{~s}^{40}$ as a template. Based on this profile, sales are observed to peak in year 9-10 and then decline at a 3.5\% annual rate owing to product obsolescence and therapeutic class competition.

FIGURE 5 shows the corresponding lifecycle profile for the mean biotechnology drug in the stylized portfolio. The mean drug in this portfolio has peak sales of $\$ 712.5$ million, which is the average of peak sales for the four products in FIG. 4. Sales increase at a rapid rate during the early years of the life cycle, reach maturity, and then slowly decline owing to product obsolescence. Competition from generics would cause a much steeper decline in sales than that shown in FIG. 5. However, this is not included in the life-cycle profiles because our basic objective is to understand how many years are typically required for an innovation to break-even before entry of a generic competitor occurs.

Given this highly skewed distribution shown in FIG. 4, the mean is heavily influenced by the top decile product. In particular, the mean peak sales value for the four-product portfolio of $\$ 712$ million is larger than three of the four products in the portfolio. This underscores the importance of a portfolio approach to product development to obtain an occasional significant commercial success. Most venture capital firms that specialize in early stage companies will invest in a large number of firms and investment projects. Most of these candidates will fail, but there is a chance to obtain one or more highly successful products that

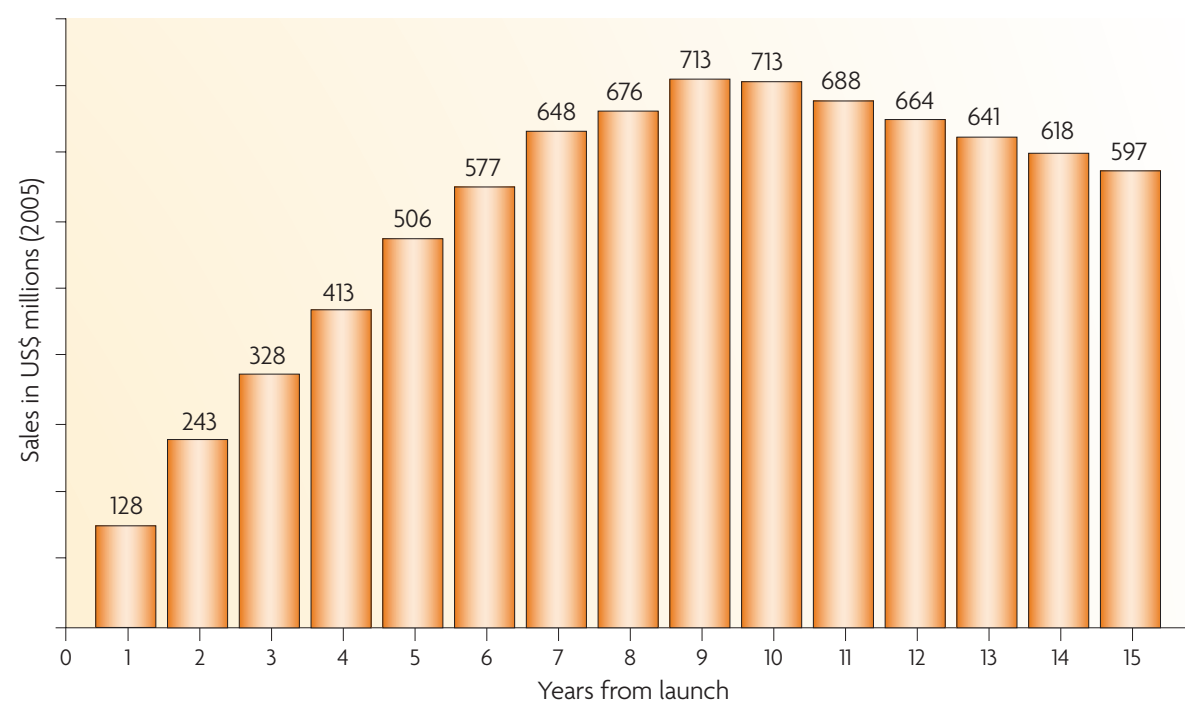

Figure 5 | Life-cycle profile for the mean product in the model biologic portfolio. The mean product in the model portfolio has peak sales of US $\$ 712.5$ million, which is the average of peak sales for the four products in FIG. 4. 


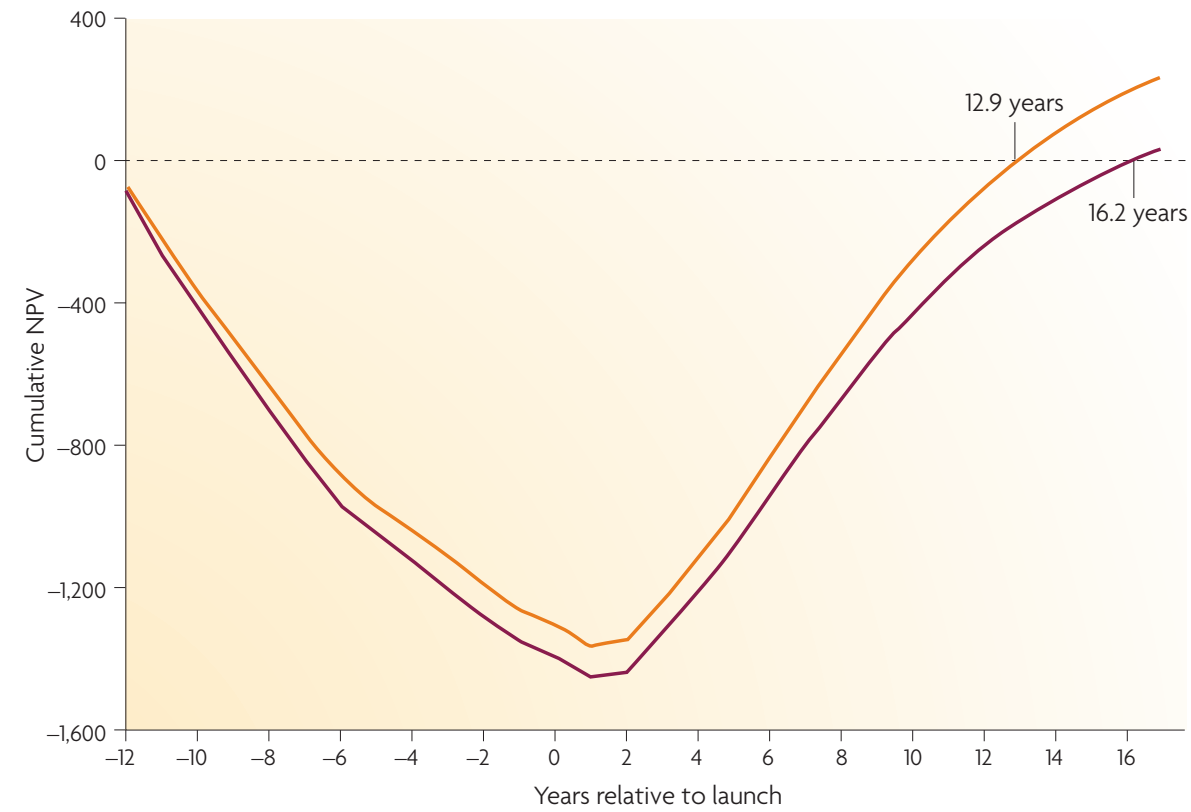

- Cumulative NPV (discount rate $=11.5 \%$ ) Cumulative NPV (discount rate $=12.5 \%$ )

Figure 6 | Break-even lifetimes for new biological entities. The figure shows the cash-flow patterns for the mean product in this portfolio analysis from the initiation of research and development (RED) to payback. When the net present values (NPV) of inflow just equals outflows, this is the break-even point at which a firm recovers its R\&D investment and earns a risk-adjusted rate of return. The breakeven time is 12.9 years for a discount rate of $11.5 \%$, and 16.2 years for a $12.5 \%$ discount rate. The key assumptions are that pre-approval R\&D costs are based on REF 16; post-approval out-of-pocket costs equal to $35 \%$ of pre-approval costs; post-approval RED costs are spread evenly over the first 8 years after launch; sales are based on historical distribution of successful biotechnology market introductions; a pre-tax contribution margin of 50\%; and all sales are measured in constant 2005 US dollars.

will drive positive overall returns. Similarly, established biotechnology companies will also carry a number of preclinical and clinical projects at different points in the life cycle with a similar strategy in mind.

R\&D and capital costs. The recent study of $\mathrm{R} \& \mathrm{D}$ costs by DiMasi and Grabowski ${ }^{16}$ found that the typical NBE introduced in recent years had a capitalized cost of \$1.24-1.33 billion, measured in 2005 US dollars, and using a discount rate of $11.5 \%$ to $12.5 \%$. These cost estimates account for both the R\&D costs of success and failures, as all these costs must be recouped from the sales of approved products. However, the analysis involved only preapproval R\&D costs, and did not include the substantial post-approval costs associated with new formulations and indications, or include the often substantial pre-approval investment in constructing manufacturing facilities.

It is instructive to consider the underlying development process for the stylized portfolio shown in FIG. 4, utilizing industry averages for development times and successes. The four-product model portfolio would first require $4-5$ years of preclinical
$R \& D$ to generate several lead candidates. The clinical process would then span an average of about 8 years, and require approximately 3.3 product candidates in clinical trials for every product introduction (that is, a $30 \%$ success ratio). However, one can still expect substantial year-to-year variability around these averages even for firms with large diversified portfolios, given the skewed distribution of outputs ${ }^{24}$.

With respect to capital expenditure requirements, it is assumed in the analysis here that firms can utilize an established plant for the commercial production of the biological products in this stylized portfolio (BOX 3, Note 6). In particular, rather than undertake a net cash flow analysis associated with the production of a new manufacturing facility, it is assumed that capital costs are captured by depreciation charges that are subsumed in the contribution margin. This approach is conservative, as some new plant construction or retrofitting of an existing plant is normally required in association with significant new product introductions. A correct financial cash-flow analysis would yield lower returns and higher break-even lifetimes, given that cash-flow outlays for new plant facilities precede in time any recovery of cash flows from net income and depreciation charges (BOX 3, Note 7).

Discount rates and contribution margins. The current analysis also assumes risk discount rates in the range of $11.5-12.5 \%$, which is reflective of the equity cost of capital for larger publicly listed biotechnology firms with multiple products on the market in recent periods. However, as discussed above, smaller publicly traded companies and non-listed private biotechnology firms would generally have much higher cost of capital, given the lack of historical track record of profitable marketable products and pipelines that are concentrated in higher and riskier early stage $\mathrm{R} \& \mathrm{D}$.

In this analysis a steady state contribution margin of $50 \%$ is used (BOX 3, Note 8 ). This value is obtained after a 2-year transition period, during which extra launch costs related to market introduction are concentrated (BOX 3, Note 9). This 50\% contribution margin is in line with the contribution margins realized by the eight largest biotechnology firms with multiple products on the market ${ }^{44}$. However, it must be kept in mind that there are few biotechnology companies that are profitable, and the universe of biotechnology firms is populated with development-stage companies whose principal assets are their human capital and intellectual property. They would be expected to realize higher costs to launch a new product than a firm with an established line of approved products.

Results. The results of the model portfolio analysis are shown in FIG. 6, which illustrates the cash-flow patterns for the mean product in this portfolio analysis from the initiation of R\&D to payback. Break-even lifetime for the portfolio occurs at 12.9 years in the case of an $11.5 \%$ real cost of capital. When a $12.5 \%$ real cost of capital is used, the breakeven lifetime is increased to 16.2 years. This illustrates the strong sensitivity of breakeven lifetimes to the discount rate. This sensitivity reflects the lengthy $\mathrm{R} \& \mathrm{D}$ investment periods associated with pharmaceutical and biopharmaceutical investments.

The analysis of returns here is designed to err on the side of underestimating breakeven lifetimes. As discussed, the assumptions on capital expenditures and the cost of capital are conservative. In addition, the lowest quintile of the sales distribution is excluded from the analysis. However, one 
factor that is relevant to consider in applying this analysis is how rapidly imitative competition will evolve for NBEs. In the short term, the innovator firms may retain some brand loyalty after the entry of follow-on biologics until prescribers and other participants become more experienced and comfortable with these entities (BOX 3, Note 10). It is generally accepted that follow-on biologics will be evaluated in terms of comparability rather than being treated as identical to the innovator's products based on evidence from at least some clinical-trial data ${ }^{45}$. For the foreseeable future, follow-on biologics also are likely to compete as therapeutic alternatives rather than as interchangeable substitutes as is the case with generic drugs. However, even if this is the case, given the prospective cost savings, there will be strong incentives to position follow-on biologics on preferred tiers through formularies and other practices of managed care organizations. Technological development and global market experience also should operate to ameliorate physician and patient concerns about their usage over time ${ }^{2}$.

\section{Conclusions and policy implications}

Over the coming decades, biopharmaceutical innovation can provide major improvements with respect to quality and length of life over an expanding set of disease areas. As has been emphasized by Woodcock ${ }^{45}$ : "It is important to ensure that facilitating the development of follow-on products through abbreviated pathways does not discourage innovation and the development of new biological products." At the same time, the costs of NBEs can be expected to account for a growing portion of the overall health-care sector budgets for new medicines. It will fall to the United States Congress to balance the objectives of innovation incentives and price competition as was the case when Congress created the Hatch-Waxman Act more than two decades ago.

There are two types of error present in the decision-making process confronting policymakers involving data exclusivity times. If data exclusivity periods are too short, new product candidates with inadequate or uncertain patent protection will be deterred. On the other hand, if data exclusivity periods are too long, price competition could be delayed beyond what is necessary to encourage innovation.

Our analysis indicates that NBEs possess demand and supply side characteristics that support a substantial exclusivity period before imitation from follow-on biologics. On the supply side, early stage research is concentrated in start-up companies that are typically financed by venture capital firms and partnerships with larger entities. The $\mathrm{R} \& \mathrm{D}$ process for NBEs is long, costly and risky. Most candidate molecules never reach the market. The market sales distribution for those molecules that do reach the market is highly skewed, with long payoff periods to profitability. With respect to medical demand and patient care, recent NBEs have resulted in several leading therapeutic advances, with important attendant benefits for human welfare. NBEs have accounted for a disproportionate share of first-in-class and best-in-class therapies in areas with high unmet needs such as oncology and rheumatoid arthritis.

Data exclusivity provides a floor in terms of the time for investors to realize returns before generics firms can enter and rely in whole or part on the innovator's data to gain its approvals. One important consideration for policymakers from basic economic principles is to align data exclusivity periods with the time necessary for the representative NBE to earn a positive risk-adjusted return on the large upfront R\&D investment. This paper presents an analysis of break-even times for NBEs to gain insights into this issue. In this regard, a simulation analysis was undertaken of a model portfolio of biotechnology products with sales that are representative of the actual historical distribution. The break-even lifetimes for the mean product were found to be between 12.9 and 16.2 years at alternative discount rates of $11.5 \%$ and $12.5 \%$, respectively.

The break-even analysis illustrates the importance of a data exclusivity period to the incentives for innovation in the pharmaceutical industry. Even diversified portfolios that achieve substantial commercial outcomes, including a blockbuster product, require lengthy payback periods. If the patents of the most successful products are subject to legal risk and challenges early in their product life cycle from follow-on competitors utilizing abbreviated regulatory pathways, this would add to the technical and commercial risks inherent in the development of NBEs. This is an especially relevant scenario in the case of NBEs because they are often based on relatively narrow patents that are vulnerable to challenges by follow-on competitors.

Legislation on follow-on biologics should be designed to strike a balance between the incentives for price and innovation competition. In particular, the legislative bills without any provisions for a data exclusivity period, or only very nominal periods of exclusivity, would have adverse effects for new biological innovation activities. Under these legislative scenarios, there would probably be an explosion in patent challenges shortly after a new product is introduced. While the right to undertake patent challenges is an integral part of the US intellectual property system, entry through abbreviated filings should be delayed until the representative NBE has had an opportunity to earn risk-adjusted break-even returns. This important concept for innovation incentives is incorporated in the US legislative proposals that provide for a substantial period of data exclusivity.

Henry Grabowski is at the Department of Economics, CB 90097, Duke University, Durham, North Carolina 27708, USA e-mail:grabow@econ.duke.edu doi: $10.1038 / \mathrm{nrd} 2532$ Published online 9 May 2008

1. Mossinghoff, G. J. Overview of the Hatch-Waxman Act and its impact on the drug development process. Food Drug Law J. 54, 187-194 (1999).

2. Grabowski, H. G., Cockburn, I. \& Long, G. The market for follow-on biologics: how will it evolve? Health Aff. 25, 1291-1301 (2006)

3. Grabowski, H. G., Ridley, D. B. \& Schulman, K. A Entry and competition in generic biologics. Manag. Decis. Econ. 28, 439-451 (2007)

4. Mansfield, E. Patents and innovation: an empirical study. Manag. Sci. 32, 173-181 (1986).

Cohen, W. M., Nelson, R. R. \& Walsh, J. Protecting Their Intellectual Assets: Appropriability Conditions and Why U. S. Manufacturing Firms Patent (Or Not) National Bureau of Economic Research (NBER) Working Paper 7552. NBER web site [online], $<$ http://www.nber.org/papers/w7552 > (2000)

6. Scherer, F. M. The Political Economy of Patent Policy Reform in the United States. John F. Kennedy School of Government (KSG), Harvard University Working Paper RWP07-042. KSG web site [online], $<$ http://ksgnotes 1.harvard.edu/Research/wpaper.nsf/ rwp/RWP07-042/Sfile/rwp 07042 scherer.pdf > (2007).

7. Verheugen, G. Future Post G-10 Pharmaceutical Strategy. Speech at the Annual Meeting of European Federation of Pharmaceutical Industry and Association. European Union web site [online], $<$ http://europa.eu/rapid/pressReleasesAction.do? reference $=$ SPEECH $/ 05 / 311$ \&format $=$ HTML\&aged $=$ 0\&language $=\mathrm{EN} \&$ guilanguage $=\mathrm{en}>(2005)$

8. Towse, A. Developing the Idea of Transferable Intellectual Property Rights (TIPP) to Incentivise $R \& D$ in Drugs and Vaccines for Neglected Diseases Appendix 1, 22-24 (Office of Health Economics, London, 2004).

9. Calfee, J. E. \& Barfield, C. Biotechnology and the Patent System: Balancing Innovation and Property Rights (AEI, Washington, DC, 2007).

10. Manheim, B. S. \& Granahan, P. \& Dow, K. J. 'Follow-on biologics': ensuring continued innovation in the biotech industry. Health Aff. 25, 394-404 (2006).

11. Burk, D. L. \& Lemley, M. A. Is patent law technology specific? Berkeley Technol. Law J. 17, 1182 (2002).

12. Grabowski, H. G. Are the economics of pharmaceutical research and development changing: productivity, patents and potential pressures. PharmacoEconomics 22 (Suppl. 2), 15-24 (2004)

13. Berndt, E. R., Mortimer, R., Bhattacharjya, A., Parece, A. \& Tuttle, E. Authorized generic drugs, price competition and consumers' welfare. Health Aff. 26, 790-799 (2007).

14. Nordhaus, W. Invention, Growth and Welfare A Theoretical Treatment of Technological Change 1-168 (Cambridge MIT Press, Cambridge, Masssachussets, 1969).

15 Scherer, F. M. \& Ross, D. Industrial Market Structure and Economic Performance 3rd edn 1-713 (Houghton Miffen, Boston, Massachussets, 1990). 
16. DiMasi, J. A. \& Grabowski, H. G. The cost of biopharmaceutical R\&D: is biotech different? Manag. Decis. Econ. 28, 469-479 (2007).

17. PAREXEL. in PAREXEL'S Pharmaceutical R\&D Statistical Sourcebook 2004/2005 (ed. Mathieu, M.) 168 (PAREXEL, Waltham, Massachussetts, 2004).

18. Berndt, E. R., Gottschalk, A. H., Philipson, T. J. \& Strobeck, M. W. Industry funding of the FDA effects of PDUFA on approval times and withdrawal rates. Nature Rev. Drug Discov, 4, 545-554 (2005).

19. Grossmann, M. Entrepreneurship in Biotechnology. Managing for Growth from Start-Up to Initial Public Offering 1-323 (Physica-Verlag, New York, 2003).

20. Myers, S. C. \& Shyum-Sunder, L. in Competitive Strategies in the Pharmaceutical Industry. (ed. Helms, R. B.) 208-237 (AEI, Washington, DC 1996).

21. DiMasi, J. A., Hansen, R. N. \& Grabowski, H. G. The price of innovation: new estimates of drug development costs. J. Health Econ. 22, 141-185 (2003).

22. Grabowski, H. G. Patents and new product development in the pharmaceutical and biotechnolog industries. Georgetown Public Policy Rev. 8, 7-24 (2003).

23. Grabowski, H. G. in Science and Cents. Exploring the Economics of Biotechnology (eds Duca, J. V. \& Yucel, M. K.) 87-104 (Federal Reserve Bank of Dallas, Texas, 2003).

24. Scherer, F. M. \& Harhoff, D. Technology policy for a world of skew - distributed outcomes. Res. Policy 29 559-566 (2000).

25. Lichtenberg, F. The impact of new drug launches on longevity: evidence from longitudinal disease-level data from 52 countries, 1982-2001. Int. J. Health Care Finance Econ. 5, 47-73 (2001)

26. Nordhaus, W. in Measuring the Gains From Medical Research: An Economic Approach (eds Murphy, K. M \& Topel, R. H.) 9-40 (Chicago University Press, Chicago, 2003).

27. Calfee, J. E. Medicines' golden age. The American March/April, 41-52 (2007).

28. Philipson, T. J. \& Jena, A. B. Who Benefits From New Medical Technologies? Estimates of Consumer and Producer Surpluses for HIV/AIDS Drugs. National Bureau of Economic Research (NBER) Working Paper No. 11810. NBER web site [online], $<$ http://www.nber.org/papers/w11810 > (2005)

29. Nordhaus, W. Schumpeterian Profits in the American Economy: Theory and Measurement. National Bureau of Economic Research (NBER) Working Paper No. 10433. NBER web site [online], < http://papers.nber. org/papers/w10433> (2004)

30. Grabowski, H. G. \& Wang Y. R. The quantity and quality of worldwide new drug introductions 1992-2003. Health Aff. 25, 452-460 (2006).

31. Smith, l. et al. 2-year follow-up of trastuzumab after adjuvant chemotherapy in HER2-positive breast cance a randomised control trial. Lancet 369, 29-36 (2007).
32. ASCOG. A Phase III randomized double-blind study of adjuvant imatinib mesylate versus placebo in patients following the resection of primary gastrointestinal stromal tumor. Clin. Adv. Hematol. Oncol. 2, 310 (2004).

33. Weaver, A. L. The impact of new biologicals in the treatment of rheumatoid arthritis. Rheumatology 43 (Suppl. 1), iii 17-iii23 (2004)

34. The Pharmaceutical Research and Manufacturers of America (PhRMA). Medicines in Development. Biotechnology 2006. PhRMA web site [online], < http:// www.phrma.org/files/Biotech\%202006.pdf > (2006).

35. Calfee, J. E. \& DuPre, E. The emerging market dynamics of targeted therapeutics. Health Aff. 25 , 1302-1308 (2006).

36. Flanagan, M. Avastin's progression. BioCentury 14 A1-A5 (2006).

37. Berndt, E. R., Cockburn, I. M. \& Grepin, K. A The impact of incremental innovation in biopharmaceuticals: drug utilization in original and supplemental indications. PharmacoEconomics 24 (Suppl. 2), 67-86 (2006).

38. Grabowski, H. G. \& Vernon, J. M. Returns to $R \& D$ on new drug introductions in the 1980s. J. Health Econ. 13, 383-406 (1994).

39. Grabowski, H. G \& Vernon, J. M. Effective patent life in pharmaceuticals. Int. J. Technol. Manag. 19, 98-120 (2000)

40. Grabowski, H. G., Vernon, J. M. \& DiMasi, J. A. Returns on research and development for 1990s new drug introductions. PharmacoEconomics 20 (Suppl. 3), 11-29 (2002).

41. Grabowski, H. G. \& Kyle, M. Generic competition and market exclusivity periods in pharmaceuticals. Manag. Decis. Econ. 28, 491-502 (2007).

42. Danzon, P., Nicholson, S. \& Sousa-Pereira, N. Productivity in pharmaceutical-biotechnology $R \& D$ : the role of experience and alliances. J. Health Econ. 24, 317-339 (2005).

43. Danzon, P., Epstein, A. \& Nicholson, S. Mergers and acquisitions in the pharmaceutical and biotech industries. Manag. Decis. Econ. 28, 307-328 (2007).

44. Centers for Medicare and Medicaid Services (CMMS). Health Care Industry Market Update: Pharmaceuticals, 10 January 2003. CMMS web site [online] $<$ http://www.cms.hhs.gov/CapMarketUpdates Downloads/hcimu 11003.pdf > (2003).

45. Woodcock, J. “Follow-on Protein Products" Statement before the Committee on Oversight and Government Reform, U. S. House of Representatives, 26 March 2007. FDA web site [online], < http://www.fda.gov/ ola/2007/protein32607.html > (2007).

46. Morrison, A. J. Biosimilars in the United States: a brief look at where we are and the road ahead. Biotech. Law Rep. 26, 463-468 (2007).

47. US Federal Trade Commission (FTC). Generic Drug Entry Prior to Patent Expiration: An FTC Study. FTC web site [online], < http://www.ftc.gov/os/ 2002/07/genericdrugstudy.pdf > (2002)
48. US Food and Drug Administration (FDA), Center for Drug Evaluation and Research. From Test Tube to Patient: Improving Health Through Human Drugs. FDA web site [online], < http://www.fda.gov/fdac/ special/newdrug/ndd toc.html > (1999).

49. DiMasi, J. A., Hansen, R. N. \& Grabowski, H. G. R\&D costs and returns by therapeutic category. Drug Inf. J. 38, 211-223 (2004)

50. Adams, C. P. \& Brantner, V. W. Estimating the cost of new drug development: is it really $\$ 802$ million? Health Aff. 25, 420-428 (2006).

51. Molowa, D. T. The State of Biologics Manufacturing JP Morgan Securities, Equity Research Healthcare Research Note. 16 February (2001).

52. Crary, C. D. Impact of KSR vs Teleflex on the Pharmaceutical Industry. Litigation Notes C. D. Crary web site [online], < www.litigationnotes.com > (2007).

53. Long, D. 2007 US Strategic Management Review: Trends, Issues, Outlook. Presentation to the 8th Institute for International Reasearch (IIR) Annual Generic Drugs Summit. Washington, DC, September 17-19. IIR web site [online], < http://www.iirusa.com genericsummit2007/24127.xml > (2007)

54. Ahlstrom, A King, R Brown, R Glaudemans, J., $\&$ Mendelson, D. Modeling Federal Cost Savings from Follow-on Biologics. Avalere Health web site [online] < http://www.avalerehealth.net/research/ docs/Modeling Budgetary Impact_of_FOBs.pdf > (2007).

55. Ferrara, N. VEGF and the quest for tumour angiogenesis factors. Nature Rev. Cancer 2, 795-803 (2002).

\section{Acknowledgements}

This research was supported in part by grants from the Pharmaceutical Research and Manufacturers of America, and the Duke University Program in Pharmaceuticals and Health Economics. The design, analysis and composition of the manuscript were conducted independently by me, and I am responsible for any errors. Early versions of this paper were presented at various forums, including the National Academy of Sciences Committee on Science Technology and Law, the Congressional Budget Office, the American Enterprise Institute, the Duke Clinical Research Institute, and the National Consumers League. I wish to thank G. Long and D. Ridley in particular for helpful comments.

\section{Competing interests statement}

The author declares competing financial interests: see web version for details.

DATABASES

The Library of Congress THOMAS: http://thomas.loc.gov/ H.R. $1038 \mid$ H.R. 1956 |H.R. 5629|S. 1695|S. 623

ALL LINKS ARE ACTIVE IN THE ONLINE PDF 